\title{
BIBLIOGRAFÍA
}

\author{
Begoña Camblor Pandiella
}

Universidad Internacional de La Rioja *

\section{DE ÁNGEL GONZÁLEZ}

\section{LIBROS DE POEMAS}

(1956). Áspero mundo, Madrid, Adonais; Madrid,Vitruvio, 2012.

(1961). Sin esperanza, con convencimiento, Barcelona, Literaturasa (Colección «Colliure»).

(1962). Grado elemental, París, Ruedo Ibérico.

(1965). Palabra sobre palabra, Madrid, Poesía para Todos.

(1967). Tratado de urbanismo, Barcelona, El Bardo; Barcelona, Lumen, 1985; Madrid, Bartleby, 2008, con lectura de Carlos Pardo.

(1968). Palabra sobre palabra, Barcelona, Seix Barral; 2. y 3. ${ }^{a}$ eds., Barcelona, Barral Editores, 1972 y 1977; 4. ${ }^{a}$ ed., Seix Barral, 1986; 1. ${ }^{a}$ ed., 10. ${ }^{a}$ imp., Barcelona, Seix Barral (Biblioteca «Los Tres Mundos»), 2011.

(1971). Breves acotaciones para una biografía, Las Palmas, Inventarios Provisionales.

(1972). Procedimientos narrativos, Santander, La Isla de los Ratones.

(1976). Muestra de algunos procedimientos narrativos y de las actitudes sentimentales que habitualmente comportan, Madrid, Turner; 2. ${ }^{\text {e }}$ d., Muestra, corregida y aumentada, de algunos procedimientos narrativos $y$ de las actitudes sentimentales que habitualmente comportan, 1977.

(1983). Prosemas o menos, Santander, Colección «Clásicos para todos los años», edición no venal; 2. ${ }^{a}$ ed., muy aumentada, Madrid, Hiperión, 1985.

(1992). Deixis en fantasma, Madrid, Los Cuadernos de la Librería Hiperión.

* Esta bibliografía ha tomado como base y punto de partida la publicada por Susana Rivera en el número monográfico que la revista Litoral dedicó a Ángel González en el año 2002, bajo el título «Ángel González. Tiempo inseguro». 
(2001). Otoños y otras luces, Barcelona, Tusquets.

(2008). Nada grave, Madrid,Visor (Colección «Palabra de Honor»).

\section{ANTOLOGÍAS}

(1980). Poemas, selección y prólogo de Ángel González, Madrid, Cátedra.

(1982). Antología poética, introducción de Luis Izquierdo, Madrid, Alianza.

(1983). Una antología, Oviedo, Automóviles Luarca S.A. (edición no venal); 2. ed., 1985.

(1988). A todo amor, introducción de Paco Ignacio Taibo I, México, Universidad Nacional Autónoma; 2. ${ }^{a}$ ed. aumentada y acompañada de un disco compacto, Madrid,Visor, 1997.

(1988). Ángel González, prólogo y selección de Susana Rivera, México DF,

Universidad Nacional Autónoma (Colección «Material de lectura»).

(1989). Ángel González, antología y estudio de Andrew P. Debicki, Madrid-Gijón, Júcar.

(1992-1993). Ángel González. Antología, selección de José Antonio

Sánchez Ibáñez, en Poesía en el Campus, 24 [«Ángel González»].

(1996). Poemas, Palma de Mallorca, Universitat de les Illes Balears, edición no venal.

(1996). Luz, o fuego, o vida, selección de Ángel González, introducción

de Víctor García de la Concha, Salamanca, Universidad.

(1997). Lecciones de cosas y otros poemas, selección e introducción

de Ángel González, Barcelona, Círculo de Lectores.

(1998). Segunda parte, selección de Ángel González, México

DF, Consejo Nacional para la Cultura y las Artes.

(2000). Poesía, selección de Norberto Cortina, La Habana, Editorial de Arte y Literatura.

(2000). 101+19=120 poemas, selección de Ángel González,

prólogo de Luis García Montero, Madrid,Visor.

(2001). La penumbra de un sueño, selección de María Payeras,

Santa Cruz de Tenerife, Cajacanarias, edición no venal.

(2002). La música y yo, Madrid,Visor.

(2002). Antología temática. La música ateológica del Eros, selección y

prólogo de Francisco Fortuny, Málaga, Diputación Provincial.

(2005). Realidad casi nube, Madrid, Aguilar (Colección «Crisolín»).

(2006). Qué sabes tú de lo que fue mi vida, prólogo de

Benjamín Prado, Cuenca, Segundo Santos. 
(2007). Biografía, edición de Julio Neira, Córdoba, Publicaciones Obra Social

y Cultural Cajasur (Colección «Los Cuadernos de Sandua», 139).

(2008). La voz de Ángel González [incluye Audio CD], Madrid, Residencia de Estudiantes.

(2008). Antología de poesía para jóvenes, prólogo, selección y entrevista

con el autor de Benjamín Prado, Madrid, Alfaguara.

(2009). La primavera avanza. Antología, edición de Susana Rivera, Madrid,Visor.

\section{TRADUCCIONES DE SU POESÍA (SELECCIÓN)}

AnCET, Jacques (1975). Neuf poètes espagnoles du vingtième siècle, Bordeaux, Plein Chant.

Brown, Steven Ford y Gutiérrez Revuelta (1993). Astonishing World:The Selected

Poems of Ángel González, 1956-1986, translated by Steven Ford Brown and Gutiérrez

Revuelta, edited by Steven Ford Brown, Minneapolis, Milkweed Editions.

Calabró, Giovanna (1980). La rosa necessaria. Poeti spagnoli contemporanei, Milán, Feltrinelli.

Darmangeat, Pierre (1963). La poésie espagnole, Paris, Ghers.

GonzÁlez Gerth, Miguel (1977). «Thirteen Poems and Some

Drawings», Texas Quarterly, XX, 1, pp.11-35.

Guereña, Jacinto Luis (1969). Anthologie bilingue de la poésie

espagnole contemporaine, Verviers, Marabout Université.

- (1977). La poésie espagnole contemporaine, Paris, Seghers.

Gutiérrez Revuelta, Pedro y Brown, Steven Ford (1989). Palabra sobre

palabra / Word Upon Word, University of Houston, edición no venal.

Hammer, Louis y Schyfter, Sara (1983). Recent Poetry of Spain, New York, Sachem Press.

López, François y Marrast, Robert (1966). La poèsie iberique

de combat, Paris, Pierre Jean Oswald Editeur.

Luti, Francesco (2001). Nel nido del cuore, Florencia, Polistampa.

- (2003). Autunni e altre luci, Florencia, Nephila.

Mares, E. A. (2007). Casi toda la música y otros poemas. Almost All

the Music and Other Poems, San Antonio, TX, Wings Press.

Mathios, Bénédicte (2013). Automnes et autres lumières, Paris, L'Harmattan.

Moura Pereira, Helder (2000). Tratado de urbanismo, Lisboa, Fenda.

Panchovska, Rada (2000). Poesía, Sofía, Sociedad Libre de Poesía.

Raissouni, Khalid y El IDrissi, Mazouar (2001). Antología poética, Tánger,

Instituto de Enseñanza Secundaria Severo Ochoa, edición no venal. 
Siebenmann, Gustav y López, José Manuel (1985). Spanische

Lyrik des 20. Jahrhunderts, Stuttgart, Philipp Reclam.

St. Martin, Hardie (1976). Roots and Wings. Poetry From

Spain (1900-1975), New York, Harper and Row.

Walsh, Donald (1977). Harsh World and other Poems,

Princeton, Princeton University Press.

\section{ENSAYO Y CRÍTICA LITERARIA}

(1952). El maestro, Barcelona, Corinto.

(1973). Juan Ramón Jiménez, Madrid-Gijón, Júcar.

(1976). El grupo poético de 1927. Antología, Madrid, Taurus; nueva ed., Madrid,Visor, 2005.

(1982). Aproximaciones a Antonio Machado, México DF, Universidad Nacional

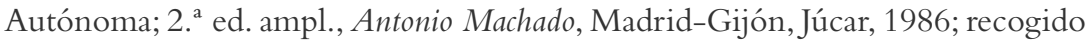
en Ángel González, Antonio Machado, Madrid, Alfaguara, 1999, pp. 41-206.

(1997). Las otras soledades de Antonio Machado. Discurso leído el día 23 de marzo de 1997, en su recepción pública, por el Excmo. Sr. Don Ángel González y contestación del Excmo. Sr. Don Emilio Alarcos Llorach, Madrid, RAE; recogido en Ángel González, Antonio Machado, Madrid, Alfaguara, 1999, pp. 253-294; reproducido en La poesía y sus circunstancias, Barcelona, Seix-Barral, 2005, pp. 101-134.

(1998). 50 años de periodismo a ratos y otras prosas, introducción y selección de Susana Rivera, Oviedo, Nobel.

(1999). Antonio Machado, prólogo de Luis García Montero, Madrid, Alfaguara.

(2005). La poesía y sus circunstancias, ed. José Luis García Martín, Barcelona, Seix-Barral.

\section{V.PRÓLOGOS}

(1968). «Prólogo», en Sabine Ulibarrí, Al cielo se sube a pie, Nuevo México.

(1976). «El grupo poético de 1927», en El grupo poético de 1927. Antología, Madrid, Taurus; recogido en La poesía y sus circunstancias, Barcelona, Seix-Barral, 2005, pp. 195-227.

(1977). «La obra poética de Gabriel Celaya», en Gabriel Celaya, Poesía, Madrid, Alianza; recogido en La poesía y sus circunstancias, Barcelona, Seix-Barral, 2005, pp. 312-332.

(1979). «Nota previa» a Antonio Machado, Antología, Madrid-Gijón, Júcar, pp. 9-16; recogido en Ángel González, Antonio Machado, Madrid, Alfaguara, 1999, pp. 217-227. (1980). «Prólogo», en Vicente Aguilera Cerni, Orlando Pelayo, Madrid-Gijón, Júcar. 
(1980). «Introducción», en Ángel González, Poemas, Madrid, Cátedra; recogido con el título "Las intenciones y la situación» en La poesía y sus circunstancias, Barcelona, Seix-Barral, 2005, pp. 403-416.

(1981). «Las Rimas de Juan Ramón Jiménez», en Juan Ramón Jiménez, Rimas, Madrid, Taurus; recogido en La poesía y sus circunstancias, Barcelona, Seix-Barral, 2005, pp. 157-176.

(1982). «Prólogo», en Paco Ignacio Taibo I, Para parar

las aguas del olvido, Madrid-Gijón, Júcar.

(1984). «Prólogo», en Luis Rius, Cuestión de amor y otros poemas, México, Promexa.

(1985). «Prólogo», en Alfredo Rodríguez, De perros y personas, Almería, Cajal.

(1992). «Prólogo», en Alberto Vega, Historia de un nudo, Gijón, Ateneo Jovellanos.

(1996). «La poesía de Álvaro Salvador», en Álvaro Salvador, Suena una música,Valencia, PreTextos; recogido en La poesía y sus circunstancias, Barcelona, Seix-Barral, 2005, pp. 388-393.

(1996). «Asturias, los poetas y Manuel Lombardero», en Manuel

Lombardero, Asturias y los poetas, Oviedo, Nobel, 1996; recogido en La poesía y sus circunstancias, Barcelona, Seix-Barral, 2005, pp. 373-378.

(1999). «En torno a Campos de Castilla», en Antonio Machado, Campos de Castilla, Madrid, Unidad Editorial; recogido en La poesía y sus circunstancias, Barcelona, Seix-Barral, 2005, pp. 94-100.

(1999). «Prólogo», en José Luis Mediavilla, Babel o felices tardes en la inopia, Oviedo, KRK.

(2000). «Acerca de Tratado de urbanismo», prólogo a la edición portuguesa bilingüe de Tratado de urbanismo, ed. Helder Moura Pereira, Lisboa, Fenda; recogido en La poesía y sus circunstancias, Barcelona, Seix-Barral, 2005, pp. 465-467.

(2002). «La música y yo», en Ángel González, La música y yo, Madrid,Visor, 2000; recogido en La poesía y sus circunstancias, Barcelona, Seix-Barral, 2005, pp. 468-470.

(2003). «Prólogo», en Pedro Casariego Córdoba, Poemas

encadenados (1977-1987), Barcelona, Seix-Barral.

(2006). «Prólogo», en Emilio Alarcos Llorach, Mester de poesía (1949-

1993), ed. José Luis García Martín, Madrid,Visor.

\section{ARTÍCULOS}

(1952). «¿Qué es el social-realismo?», Índice, 51.

(1963). «Poesía y compromiso», en Poesía última, ed. Francisco Ribes, Madrid,

Taurus, pp. 57-59; recogido en Pedro Provencio, Poéticas españolas contemporáneas.

La generación del 50, Madrid, Hiperión, 1988, pp. 23-25; recogido en La

poesía y sus circunstancias, Barcelona, Seix-Barral, 2005, pp. 450-452. 
(1965). «Poética. Defensa de la poesía social», en Poesía social, ed. Leopoldo de Luis, Madrid, Alfaguara, pp. 291-292; recogido en Pedro Provencio, Poéticas españolas contemporáneas. La generación del 50, Madrid, Hiperión, 1988, pp. 25-26; recogido en La poesía y sus circunstancias, Barcelona, Seix-Barral, 2005, pp. 453-454.

(1968). «Respuestas / Cuestionario», en Antología de la nueva poesía española, ed. José Batlló, Madrid, El Bardo, pp. 342-344; recogido en Pedro Provencio, Poéticas españolas contemporáneas. La generación del 50, Madrid, Hiperión, 1988, pp. 26-28.

(1975). «Tono y poesía: a propósito de Jaime Gil de Biedma», Prohemio,VI, pp. 119-133.

(1975). «Originalidad del pensamiento de Antonio Machado», Peña

Labra. Pliegos de Poesía, 16, pp. 27-28; recogido en Ángel González, Antonio Machado, Madrid, Alfaguara, 1999, pp. 209-215.

(1976). «Posguerra y promiscuidad», Diario 16, 28 de septiembre.

(1976). «La de 1936. Una generación frustrada», Diario 16, 27 de octubre.

(1977). "Comentarios en torno a un poema de Antonio Machado», en Estudios ofrecidos a Emilio Alarcos Llorach, tomo I, Oviedo, Universidad, pp. 323-335; recogido con el título «El viajero: retrato del artista como viejo fotógrafo», en Ángel González, Antonio Machado, Madrid, Alfaguara, 1999, pp. 157-175.

(1977). «Celaya, 30 años después (Juan de Leceta)», Triunfo, 730, pp. 42-45.

(1977). «Francisco Villaespesa: Posibles causas de un injusto olvido», Triunfo, 778, pp. 46-48; recogido en La poesía y sus circunstancias, Barcelona, Seix-Barral, 2005, pp. 80-88.

(1977). «La elegía como forma poética en Machado»,

Papeles de Son Armadans, CCLIX, pp. 23-51.

(1980). «Pintor de historia. Sobre la pintura de Orlando Pelayo", Los Cuadernos del Norte, 1, pp. 43-47.

(1980). «Poesía española contemporánea», Los Cuadernos del Norte, 3, pp. 4-7; recogido en La poesía y sus circunstancias, Barcelona, Seix-Barral, 2005, pp. 379-387.

(1981). «El primer Juan Ramón en su contexto», Los Cuadernos del Norte, 10, pp. 44-53; recogido en VV. AA., Ángel González: Verso a verso, Oviedo, Caja de Ahorros de Asturias (Colección «Libro-Homenaje»), 1987, pp. 174-184; recogido en La poesía y sus circunstancias, Barcelona, Seix-Barral, 2005, pp. 135-156.

(1981). «Presencia de Espronceda en la Rima LXXII de Bécquer», Romance Notes, 2, XXII, pp. 1-5.

(1981). «Ramón Pérez de Ayala: verbalización del paisaje y credo estético», en Simposio Internacional: Ramón Pérez de Ayala, ed. Pelayo H. Fernández, University of New Mexico, pp. 148-156; recogido en VV.AA., Ángel González:Verso a verso, Oviedo, Caja de Ahorros de Asturias (Colección «Libro-Homenaje»), 1987; recogido en La poesía y sus circunstancias, Barcelona, Seix-Barral, 2005, pp. 181-194. 
(1982). «El todo y las partes», Revista de Bellas Artes, julio, pp. 20-22.

(1983). «Sobre las fuentes literarias: con motivo de un texto de Espronceda y un pre-texto de Góngora», Revista de Estudios Hispánicos, 17, pp. 81-87.

(1984). «La Regenta va al teatro», en VV.AA., La Regenta cien años después, Oviedo, La Ferrería, 1984; recogido en VV. AA., Ángel González: Verso a verso, Oviedo, Caja de Ahorros de Asturias (Colección «Libro-Homenaje»), 1987, pp. 209-212; recogido en La poesía y sus circunstancias, Barcelona, Seix-Barral, 2005, pp. 41-48.

(1984). «Sobre poesía y poetas», Peña Labra. Pliegos de Poesía, 52; recogido en Litoral [«Ángel González. Tiempo inseguro»], 233 (2002), p. 59; recogido en La poesía y sus circunstancias, Barcelona, Seix-Barral, 2005, pp. 458-459.

(1984). «Coloquio sobre poesía» (con Claudio Rodríguez, José Agustín Goytisolo, Francisco Brines, José Manuel Caballero Bonald, Carlos Sahagún, Fernando Quiñones), Olvidos de Granada, 13, pp. 129-145.

(1985). «Palabras pronunciadas en el acto de entrega de los Premios Príncipe de Asturias 1985», Barcelona, edición no venal de Manuel Lombardero; recogido en VV. AA., Ángel González: Verso a verso, Oviedo, Caja de Ahorros de Asturias (Colección «Libro-Homenaje»), 1987, pp. 213-215.

(1987). «La intertextualidad en la obra de Blas de Otero», en Al amor de Blas de Otero, coord. José Ángel Ascunce, San Sebastián, Universidad de Deusto, pp. 63-75; recogido en La poesía y sus circunstancias, Barcelona, Seix-Barral, 2005, pp. 266-286. (1987). «Ramón de Campoamor: una semblanza», en VV.AA., Ángel González: Verso a verso, Oviedo, Caja de Ahorros de Asturias (Colección «Libro-Homenaje»), 1987, pp. 229-234; recogido en La poesía y sus circunstancias, Barcelona, Seix-Barral, 2005, pp. 49-59.

(1987). «Inquisición de Gabriel Celaya», en VV.AA., Noticia de Gabriel Celaya, Madrid, Ministerio de Cultura, pp. 11-12.

(1989). «Azul y la poesía española del siglo XX», Revista Hispánica Moderna, XLII, 2, pp.127-135; recogido en Ángel González, Antonio Machado, Madrid, Alfaguara, 1999, pp. 229-252; recogido en La poesía y sus circunstancias, Barcelona, Seix-Barral, 2005, pp. 60-79. (1989). «1957», Efemérides, Madrid, Agencia Efe, p. 118.

(1989). «Viaje a Región», El Urogallo, 35, pp. 60-62; recogido en La poesía $y$ sus circunstancias, Barcelona, Seix-Barral, 2005, pp. 336-341.

(1990). «Para que yo me llame Ángel González», Anthropos, 109, pp. 19-29.

(1990). «Jaime Gil de Biedma: breve evocación de una larga amistad», Revista de Occidente, 110-111, pp. 17-20.

(1991). «El exilio en España y desde España», en El exilio de las Españas de 1939 en las Américas: "¿Adónde fue la canción?», coord. José María 
Naharro-Calderón, Barcelona, Anthropos, 1991, pp. 195-209; recogido en

La poesía y sus circunstancias, Barcelona, Seix-Barral, 2005, pp. 249-265.

(1993). «La poesía de la Generación del 27», Cuadernos Hispanoamericanos, 514-515, pp.

39-51; recogido en La poesía y sus circunstancias, Barcelona, Seix-Barral, 2005, pp. 228-246.

(1994). «Intertextualidad e interdiscursividad en la poesía de Gabriel

Celaya», en Gabriel Celaya: contexto, ética y estética, ed. José Ángel Ascunce,

San Sebastián, Universidad de Deusto, pp. 91-105; recogido en La poesía

$y$ sus circunstancias, Barcelona, Seix-Barral, 2005, pp. 312-332.

(1995). «Laudatio dedicada a Emilio Alarcos», en Nombramiento de Hijo Adoptivo

de Oviedo de don Emilio Alarcos Llorach, Oviedo, Ayuntamiento, pp. 3-10.

(1998). «La generación del 98. Un segundo Siglo de Oro», Ronda Iberia, enero, pp. 71-75.

(1998). «¿Por qué escribo?», El País Semanal, 4 de enero, p. 35; recogido en

Litoral [«Ángel González. Tiempo inseguro»], 233 (2002), p. 5; recogido en

La poesía y sus circunstancias, Barcelona, Seix-Barral, 2005, pp. 462-464.

(1998). «Completamente viernes: el amor entretanto y entre todo», Litoral [«Luis García

Montero. Complicidades»], ed. Antonio Jiménez Millán, 217-218, pp. 108-111;

recogido en La poesía y sus circunstancias, Barcelona, Seix-Barral, 2005, pp. 394-400.

(1998). "Adiós, siglo XX. Tus amigos no te olvidan»,

suplemento «La Esfera», El Mundo, 14 de marzo.

(2000). «Notas para una etopeya de J. M. Caballero

Bonald», Revista Atlántica, 22, pp. D05-D06.

(2001). "La letra P platica de sí misma», en Al pie de la

letra, Salamanca, Caja Duero, pp. 171-175.

(2001). «Imagen de Emilio Alarcos Llorach: el hombre, el humanista, el poeta», en Homenaje a Emilio Alarcos Llorach, Madrid, Gredos, pp. 49-61; recogido en

La poesía y sus circunstancias, Barcelona, Seix-Barral, 2005, pp. 354-372.

(2001). «Notas para un anteproyecto de retrato imposible»,

República de las Letras, 70, pp. 19-21.

(2002). «Sobre la poesía: un alegato», La Estafeta del Viento, 1; recogido en

La poesía y sus circunstancias, Barcelona, Seix-Barral, 2005, pp. 477-484.

(2002). «El ejercicio de la sátira», Letra Internacional, primavera, pp. 89-91.

(2002). «Todos los comienzos», Litoral [«Ángel González.

Tiempo inseguro»], 233, pp. 44-55.

(2002). «Unas palabras para la poesía. Palabras pronunciadas en el acto de entrega del

Premio Internacional Reina Sofia de Poesía Ibero-Americana [1996]», Litoral [«Ángel 
González. Tiempo inseguro»], 233, pp. 322-326; reproducido con el título «La poesía y otras dudas» en La poesía y sus circunstancias, Barcelona, Seix-Barral, 2005, pp. 471-476.

(2002). «Viaje por los alrededores de Don Quijote», Madrid, Publicaciones

de la Federación de Asociaciones de Profesores de Español; recogido en La poesía y sus circunstancias, Barcelona, Seix-Barral, 2005, pp. 27-40.

(2003). «Soledades: acta de nacimiento de un poeta mayor», ABC Cultural, 14 de junio, p. 4; recogido en La poesía y sus circunstancias, Barcelona, Seix-Barral, 2005, pp. 89-93.

(2004). «La poesía desnuda», en Cartografía poética. 54 poetas españoles escriben sobre un poema preferido, ed. Anthony L. Geist y Álvaro Salvador, Sevilla, Renacimiento, pp. 154158; recogido en La poesía y sus circunstancias, Barcelona, Seix-Barral, 2005, pp. 176-180.

(2005). «Carta a Gabriel Celaya con motivo de su doctorado honoris causa por la Universidad de Granada», en La poesía y sus circunstancias, Barcelona, Seix-Barral, pp. 333-335.

(2005). «¿Malos tiempos para la poesía?», en La poesía y sus circunstancias, Barcelona, Seix-Barral, pp. 460-461.

\section{SOBRE ÁNGEL GONZÁLEZ}

\section{LIBROS Y PUBLICACIONES MONOGRÁFICAS}

Alarcos Llorach, Emilio (1969). Ángel González, poeta (Variaciones críticas), Oviedo, Universidad; reproducido en Emilio Alarcos Llorach, La poesía de Ángel González, Oviedo, Nobel, 1996, pp. 7-190.

- (1996). La poesía de Ángel González, Oviedo, Nobel.

Anthropos (1990). «Ángel González. Una poética de la experiencia y la cotidianidad», 109.

BAEna, Enrique (2007). Metáforas del compromiso (configuraciones de la poética actual y creación de Ángel González), Madrid, Cátedra.

Browne, Peter E. (1997). El amor por lo (par)odiado: la poesía de Gloria Fuertes y Ángel González, Madrid, Pliegos.

Candel Vila, Consuelo (2003). El realismo dialéctico en las poéticas de Luis Rosales, Ángel González y Luis García Montero, Valencia, Universidad.

Cuadernos Hispanoamericanos (2008). «Los Complementarios. Ángel González», Extra 17.

Debicki, Andrew, P. (1989). Ángel González, Madrid-Gijón, Júcar. 
— y UGalde, Sharon Keefe, eds. (1991). En homenaje a Ángel González: ensayos, entrevista, poemas, Boulder, University of Colorado.

Guerrero, José, Peregrina, Elena y Salvador, Álvaro, coords. (2004). Ángel González, un clásico de nuestro tiempo, Almería, Universidad.

Lasheras, Javier, coord. (2008). Lúcido Ángel. Ángel González (19252008). Exposición bibliográfica, Oviedo, Biblioteca Pública de Asturias.

Litoral (2002). «Ángel González. Tiempo inseguro», 233, ed. Susana Rivera.

Luna de Abajo (1985). "Guía para un encuentro con Ángel González», 3;

3. ${ }^{\text {a }}$ ed. aum., Oviedo, Luna de Abajo / Tribuna Ciudadana, 1997.

Mathios, Bénédicte (2009). Une lecture de l'oeuvre d'Ángel

González: corps et écriture, Berna, Peter Lang.

Miller, Martha (1995). Politics and Verbal Play: The Ludic Poetry of Ángel González, Fairleigh Dickinson University Press.

Payeras Grau, María (2009). El sueño de la realidad. Poesía y poética de Ángel González, Santa Cruz de Tenerife, La Página.

Peña Labra. Pliegos de Poesía (1984). «Ángel González, muestra muy breve», 52.

Poesía en el Campus (1992-1993). «Ángel González», 24.

Rivera, Susana y Ruiz Fábrega, Tomás, eds. (1987). Simposio-

Homenaje a Ángel González, Madrid, José Esteban Editor.

Romano, Marcela (2003). Almas en borrador. Sobre la poesía de Ángel

González y Jaime Gil de Biedma, Mar del Plata, Martín.

Salvador, Álvaro (2009). Ángel González: el intelectual y su memoria, Granada, Universidad.

VV.AA. (1987). Ángel González:Verso a verso, Oviedo, Caja de

Ahorros de Asturias («Colección Libro-Homenaje»).

- (1987). Encuentros con el 50, Oviedo, Fundación Municipal de Cultura.

- (1997). Palabras sobre Ángel González, Oviedo, ALSA.

- (1998). Ángel González en la generación del 50. Diálogo con los poetas de la experiencia, Oviedo, Tribuna Ciudadana.

Zurgai (2005). «Con Ángel González», junio. 


\section{ARTÍCULOS, CAPÍTULOS}

\section{DE LIBRO Y RESEÑAS}

Abad, Francisco (1990). «Crítica literaria y lengua poética de Ángel González», Anthropos [«Ángel González. Una poética de la experiencia y la cotidianidad»], 109, pp. 55-57.

Alarcos Llorach, Emilio (1990). «Recato y elegía», Anthropos [«Ángel González. Una poética de la experiencia y la cotidianidad»], 109, pp. 52-54; recogido en La poesía de Ángel González, Oviedo, Nobel, 1996, pp. 293-307; reproducido en Litoral [«Ángel González. Tiempo inseguro»], 233 (2002), pp. 144-149.

- (1997). «Ángel González en perpetua imaginaria», Luna de Abajo ["Guía para un encuentro con Ángel González»], 3, 3. a ed. aum., p. 35.

- (1997). «Otra vez sobre Ángel: del compromiso al desasimiento», Clarín. Revista de Nueva Literatura, 11, pp. 3-7.

- (1997). «Contestación al discurso del ingreso de Ángel González en la RAE», en Ángel González, Las otras soledades de Antonio Machado, Madrid, RAE, pp. 51-71.

- y GonzÁlez, Ángel (1987). «El poeta y el crítico», en Ángel González: Verso a verso, Oviedo, Caja de Ahorros de Asturias ("Colección Libro-Homenaje»), pp. 51-94.

Albiac Blanco, María Dolores (1992-1993). «Breve conjugación del tiempo en la poesía de Ángel González», en Poesía en el Campus ["Ángel González»], 24, pp. 3-8.

Alfaya, Javier (1976). «Un nuevo libro de Ángel González», Triunfo, 709, pp. 51-52.

- (1976). «Un grupo clave de poetas», Triunfo, 726, pp. 60-61.

Alonso Valero, Encarna (2004). «"El otoño se acerca con muy poco ruido": aproximación a Otoños y otras luces de Ángel González», Ciberletras, 12. http://www.lehman.cuny.edu/ciberletras/v12/alonsovalero.htm.

Alvarado Tenorio, Harold (1980). «Ángel González», en Cinco poetas de la generación del cincuenta (A. González, J. M. Caballero Bonald, C. Barral, J. Gil de Biedma y F. Brines), Bogotá, La Oveja Negra, pp. 25-36.

Álvarez, Faustino F. (1987). «Ángel González. Historia de un amigo», en Ángel González: Verso a verso, Oviedo, Caja de Ahorros de Asturias («Colección Libro-Homenaje»), pp. 21-22.

- (1997). «Apunte sobre Ángel González y Antonio Machado», Luna de Abajo

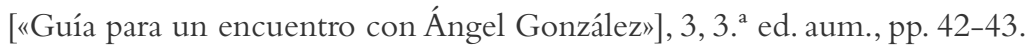

Álvarez Castro, Luis (2010). «El éxito de todos los fracasos: la metapoesía en el primer Ángel González», Anales de la Literatura Española Contemporánea, 35, pp. 259-286.

Argüelles, José Domingo (1999). «Ángel González, un raudo soplo fresco», El Universal, 17 de abril, pp. 1 y 4. 
Armisén, Antonio (1992-1993). «Sobre el hombre y el nombre. Notas de lectura a "Para que yo me llame Ángel González”», en Poesía en el Campus [“Ángel González»], 24, pp. 10-15; versión ampliada en Grama y Cal, 2 (1998), pp. 131-145.

Avello, M. F. (1962). «Ángel González. Sin esperanza, con convencimiento", Región, 21 de febrero.

- (1970). «Reseña de Ángel González, poeta, de Emilio Alarcos Llorach», La Nueva España, 29 de enero.

- (1978). «Ángel González, poeta», La Nueva España, 30 de abril.

- (1997). «Para que yo recuerde a Ángel González», Luna de Abajo ["Guía para un encuentro con Ángel González»], 3, 3. a ed. aum., pp. 17-19.

Ayala, Francisco (1997). «Apuntes para la biografía de los poetas», El País, 9 de junio; recogido en Luna de Abajo ["Guía para un encuentro con Ángel González»], 3, 3. a ed. aum., 1997, pp. 60-64; recogido en Litoral [«Ángel González. Tiempo inseguro»], 233 (2002), pp. 133-137.

Ayuso, José Paulino (1988). «Ensayo de una poética para un tiempo incierto y melancólico: consideraciones sobre Ángel González con una glosa becqueriana», Dicenda, 7, pp. 231-234.

Baena, Enrique (1981). «Realidad y utopía. Sobre Áspero mundo de Ángel González», Analecta Malacitana, IV, 1, pp. 165-186.

— (1985). «La instancia sentimental y utópica de Ángel González», Sur, 22 de junio. - (1988). «Plenitud de lo posible: tiempo individual y exigencia histórica en Ángel González», en Ángel González, Málaga, Centro Cultural Generación del 27.

- (1990). «La imagen poética de la experiencia: ironía y humor en Ángel González», Anthropos [«Ángel González. Una poética de la experiencia y la cotidianidad»], 109, pp. 104-109.

- (1991). «La invención de Ángel González en el origen de su obra poética», en En homenaje a Ángel González: ensayos, entrevista, poemas, ed. Andrew P. Debicki y Sharon Keefe Ugalde, Boulder, University of Colorado, pp. 37-57.

Bagué Quílez, Luis (2005). «Las huellas de una complicidad: Ángel González y la última poesía española», Zurgai [«Con Ángel González»], junio, pp. 110-117.

Barral, Carlos (1997). «Fragmentos de Penúltimos castigos», Luna de Abajo ["Guía para un encuentro con Ángel González»], 3, 3. a ed. aum., p. 30.

Benedetti, Mario (1968). «Ángel González frente a la realidad abrumadora", en Sobre artes y oficios, Montevideo, Alfa.

Benet, Juan (1997). «Mi amistad con Ángel González», Luna de Abajo ["Guía para un encuentro con Ángel González»], 3, 3. ${ }^{a}$ ed. aum., p. 41. 
Benítez Reyes, Felipe (2008). «La gravedad de Ángel González», Clarín. Revista de Nueva Literatura, 77, pp. 50-53.

Benito Argüelles, Juan (1987). «Perfil humano de Ángel González», en Ángel González:Verso a verso, Oviedo, Caja de Ahorros de Asturias («Colección Libro-Homenaje»), pp. 18-20.

- (1997). «Reflexiones sobre Ángel González», Luna de Abajo [«Guía para un encuentro con Ángel González»], 3, 3. a ed. aum., pp. 20-23.

Benson, Douglas K. (1979). «Ángel González y Muestra: Las perspectivas múltiples de una sensibilidad irónica», Revista Hispánica Moderna, 40,1-2, pp. 42-59.

- (1981). «La ironía, la función del hablante y la experiencia del lector en la poesía de Ángel González», Hispania, 64, pp. 570-581.

- (1982). «Linguistic Parody and Reader Response in the Works of Ángel González», Anales de la Literatura Española Contemporánea, 7, pp. 11-30. - (1991). «Las voces de Ángel González», en En homenaje a Ángel González: ensayos, entrevista, poemas, ed. Andrew P. Debicki y Sharon Keefe Ugalde, Boulder, University of Colorado, pp. 7-23.

- (1991). «Heteroglosia en la poesía de Ángel González», en Critical Essays on the Literatures of Spain and Spanish America,VII, Boulder, Society of Spanish and Spanish-American Studies, pp. 11-18.

- (2001). «Postmodern Irony and the Discourse of Love in Ángel González’s Sin esperanza, con convencimiento», Crítica Hispánica, 23, pp. 60-69.

Bernat Vistarini, Antonio (1990). «En compañía de Ángel González (Sobre Áspero mundo)», Anthropos ["Ángel González. Una poética de la experiencia y la cotidianidad»], 109, pp. 101-103.

Blanc, Mario A. (1989). "Una lectura en perspectiva de dos poemas de Ángel González», Discurso literario,VI, 2, pp. 311-327.

Borja, Carmen (1990). «El sentimiento elegíaco en la poesía de Ángel González», Anthropos [«Ángel González. Una poética de la experiencia y la cotidianidad»], 109, pp. 57-59.

Brines, Francisco (2008). «Ángel González, siempre vivo y cercano», Cuadernos Hispanoamericanos [«Los Complementarios. Ángel González»], Extra 17, pp. 17-18.

Brower, Gary L. (1974). «Breves acotaciones para una bio-bibliografia de la "vidobra” de Ángel González", Mester, 5, pp.10-12.

— (1974). «Ángel González: A Portrait», Mundus Artium, 7, pp. 145-151.

Bryce Echenique, Alfredo (2002). «Ostras profundamente fritas», Litoral [«Ángel González. Tiempo inseguro»], 233, pp. 164-166. 
— (2008). «Con Ángel en Albuquerque», Cuadernos Hispanoamericanos

[«Los Complementarios. Ángel González»], Extra 17, pp. 19-21.

Buero Vallejo, Antonio (1997). «A Ángel González», Luna de Abajo [«Guía

para un encuentro con Ángel González»], 3, 3. a ed. aum., pp. 13-16.

Caballero Bonald, José Manuel (1963). «Reseña de Grado elemental», Ínsula, 195, p. 4.

- (1997). «En Madrid, New Mexico», Luna de Abajo ["Guía para un encuentro con Ángel González»], 3, 3. a ed. aum., pp. 27-29; reproducido en Anthropos [«Ángel González. Una poética de la experiencia y la cotidianidad»], 109 (1990), pp. 117-118; reproducido en Litoral [«Ángel González. Tiempo inseguro»], 233 (2002), pp. 167-169.

- (2005). «La poesía como descubrimiento», Zurgai

[«Con Ángel González»], junio, pp. 6-7.

- (2008). «Desaprendizaje», Cuadernos Hispanoamericanos [«Los

Complementarios. Ángel González»], Extra 17, pp. 104-105.

— (2008). «Ángel González, In Memoriam», Barcarola, 71-72, pp. 443-444.

Caffarato, Mauro (2008). «La importancia de llamarse Ángel González», Cuadernos

Hispanoamericanos [«Los Complementarios. Ángel González»], Extra 17, pp. 84-97.

Calleja Pérez, Seve (2005). «Ángel González, maestro de

poetas», Zurgai [«Con Ángel González»], junio, p. 4.

Candau, Antonio (2010). «Nada grave, con estrambote: un túmulo poéticomediático para Ángel González», en Necrofilia y necrofobia. Representaciones de la muerte en la cultura hispánica, eds. Ricardo de la Fuente Ballesteros y Jesús Pérez-Magallón, Valladolid, Universitas Castellae, pp. 19-29.

Candel Vila, Xelo (2002). «Ángel González y su diálogo con el discurso dialéctico de Antonio Machado», Litoral [“Ángel González. Tiempo inseguro»], 233, pp. 194-201.

Cañas, Dionisio (1980). «La polifonía poética de Ángel

González», El País, 17 de agosto, p. 5.

Carnero, Guillermo (1976). «El último libro de Ángel González, alumbramiento de muchos caminos», Informaciones, 16 de diciembre.

Carrasco Molina, José (2008). «Ángel González: el hombre y

el poeta», Tonos Digital, 16. https://www.um.es/tonosdigital/ znum16/secciones/perfiles-1-Perfil_angel_gonzalez.htm.

— (2009). «Ángel González, espía de palabras», Tonos Digital, 17. https:// www.um.es/tonosdigital/znum17/secciones/estudios-3.htm.

Carreño Espinosa, Francisco (1999). «Consideraciones sobre la ironía, el tiempo y la metapoesía en Prosemas o menos de Ángel González», Epos. Revista de Filología, 15, pp. 213-234. 
Castañón, L. (1967). «El recital», Región, 9 de mayo.

- (1967). «Díptico poético», Región, 23 de julio.

Cilleruelo, José Ángel (1990). «Dimensión de la ciudad en la poesía

de Ángel González», Anthropos [“Ángel González. Una poética

de la experiencia y la cotidianidad»], 109, pp. 60-63.

Clavería, Carlos (1990). «Un detalle sobre la partenogénesis de

Ángel González», Anthropos [«Ángel González. Una poética de

la experiencia y la cotidianidad»], 109, pp. 114-116.

Corbacho Cortés, Carolina (1996). «El humor y la poética en Ángel

González», Anuario de Estudios Filológicos, 19, pp. 149-162.

Crémer,Victoriano (1968). «Reseña de Palabra sobre palabra», Proa, 7 de julio.

Crespo Martín, Salvador (1999). «Amor, erotismo y creación poética en la

poesía de Ángel González», en Congreso Internacional Amor y Erotismo en la

Literatura, coord.Vicente González Martín, Madrid, Caja Duero, pp. 239-248.

Crespo Matellán, Salvador (1989). «Algunos recursos lingüísticos de la ironía en la poesía de Ángel González», en VV. AA., Philologica. Homenaje a don Antonio Llorente, II, Salamanca, Universidad, pp. 281-287.

- (1996). «El destinatario plural en la poesía de Ángel González», en VV.AA., Actas del Congreso Jaime Gil de Biedma y su generación poética, II, [Zaragoza], Diputación General de Aragón, pp. 369-375.

- (2001). «La mezcla de registros y otros recursos expresivos en la poesía de Ángel González», en Nuevas aportaciones al estudio de la lengua española: investigaciones filológicas, coord. José Antonio Bartol, Madrid, Luso-Española Ediciones, pp. 393-403.

Cruz, Juan (1995). «Afirmación de Ángel González»,

La Gaceta de Canarias, 10 de septiembre.

— (1996). «1936», El País, 8 de junio.

— (2005). «Una manera de andar», Zurgai [«Con Ángel González»], junio, p. 12.

— (2008). «Muchas veces Ángel», Cuadernos Hispanoamericanos [«Los

Complementarios. Ángel González»], Extra 17, pp. 50-55.

— (2009). «Ángel González, poeta del tiempo», Campo de Agramante, 11, pp. 115-123.

Daydí-Tolson, Santiago (1985). "Aspectos orales de la poesía social

española de posguerra», Hispanic Review, 53, pp. 449-466.

- (1988-1989). «Oralidad y escritura en la poesía de Ángel

González», Siglo XX / 20 Century, 6, pp. 1-10.

Deвіскі, Andrew, P. (1987). «Ángel González: transformación y perspectiva», en Poesía del conocimiento: La generación española de 1956-71, Madrid-Gijón, Júcar, pp. 109-138. 
- (1987). «Poesía como un acto de conocimiento: el texto, la intertextualidad y la experiencia de la lectura en la generación de los 50», en Simposio-homenaje a Ángel González, eds. Susana Rivera y Tomás Ruiz Fábrega, Madrid, José Esteban, pp. 55-69.

- (1990). «Prosemas o menos: un libro de la posmodernidad», en Encuentros con el 50: la voz poética de una generación, Oviedo, Fundación Municipal de Cultura, pp. 159-166.

- (2002). «Símbolo y experiencia en Otoños y otras luces», Litoral [«Ángel González. Tiempo inseguro»], 233, pp. 202-205.

Delgado, Bernardo (1977). «Las tres voces de Ángel

González», Jugar con Fuego, 3-4, pp. 77-86.

Deters, Joseph (1999). «El desafío de la verdad en la poesía de Ángel González», Hispanic Journal, XX, 2, pp. 239-248.

- (1999). «Love, Intertext and Criticism in Ángel González's Tratado de urbanismo», Ojáncano, 17, pp. 45-63.

— (2003). «Notes on Love and Poetry: Ángel González’s Breves acotaciones para una biografía», Hispanófila, 137, pp. 45-54.

DíAz, Francisco y Matas, Araceli (1979). «La crisis de la utopía en Ángel González (a propósito de Muestra corregida y aumentada...)», Mayurqa, 17, pp. 163-165.

Díaz Castañón, Carmen (1973). «Un cuarto tiempo para una metáfora», Papeles de Son Armadans, 68, pp. 167-176.

- (1987). «Avanzaba de espaldas aquel río...», en Ángel González: Verso a verso, Oviedo, Caja de Ahorros de Asturias («Colección Libro-Homenaje»), pp. 23-28.

Díaz de Castro, Francisco (1990). «Lectura de Prosemas o menos de Ángel González», Anthropos ["Ángel González. Una poética de la experiencia y la cotidianidad»], 109, pp. 44-51; reproducido en Poesía española contemporánea: 14 ensayos críticos, Málaga, Universidad, pp. 203-223.

- (2002). «Lectura de Deixis en fantasma», Litoral ["Ángel

González. Tiempo inseguro»], 233, pp. 206-216.

— (2004). «Los otoños de Ángel González», en Ángel González, un clásico de nuestro tiempo, coords. José Guerrero, Elena Peregrina y Álvaro Salvador, Almería, Universidad, pp. 93-107; parcialmente reproducido en Zurgai [«Con Ángel González»], junio 2005, pp. 104-109.

DíAz-Plaja, Guillermo (1971). «Palabra sobre palabra de Ángel González», en Cien libros españoles, Salamanca, Anaya, pp. 105-108.

Diego, Gerardo (1993). "Áspero mundo», en Gerardo Diego y Adonais, ed. Rafael Morales, Madrid, Rialp; recogido en Litoral [«Ángel González. Tiempo inseguro»], 233 (2002), pp. 130-132. 
Domínguez Rey, A. (1976). «Poesía del realismo crítico», El País, 18 de agosto.

Doval, José (1987). «Retrato de familia con poeta», en Ángel González:Verso a verso, Oviedo, Caja de Ahorros de Asturias («Colección Libro-Homenaje»), pp. 143-145.

Erdocia Castillejo, Carolina, Beti, Arantxa y Amorós, Leonor (1986).

"Ángel González, Tratado de urbanismo», Mundaiz, 32, pp. 77-90.

Esteban, José (1973). «La segunda salida de Palabra sobre palabra», Triunfo, 536, 6 de enero.

- (1997). «El poeta Ángel González», Luna de Abajo ["Guía para un encuentro con Ángel González»], 3, 3. ${ }^{2}$ ed. aum., pp. 36-38.

- (2002). «Otro tiempo vendrá, distinto a este», Litoral [«Ángel

González. Tiempo inseguro»], 233, pp. 170-171.

FAJARDO, Salvador J. (1995). «Digresión creadora en "La palabra” de

Ángel González», Hispanic Journal, XVI, 1, Spring, pp. 177-186.

Ferrari, Marta B. (2001). «El otro lado del poema: la antipoesía de Ángel González», en La coartada metapoética, Mar del Plata, Editorial Martín, pp. 129-168.

- (2013). «Sobre ideología y estética en Ángel González», Tropelías, 19, pp. 269-280.

Ferrer Solá, Jesús (2001). «Demoledora función del recuerdo»,

suplemento «Caballo verde», La Razón, 18 de mayo.

Fisher, Diane R. (1991). «The Voices of Logocentrism and Decentering in Two

Poems by Ángel González», Revista Canadiense de Estudios Hispánicos, 16, pp. 45-59.

— (1993). «Apostrophe and Ironic Duality in "Hecho" and "Orador

implacable y solitario” by Ángel González», Hispanófila, 107, pp. 23-32.

- (1993). «The Deconstruction of Irony in the Poetic Trajectory of

Ángel González», Revista Hispánica Moderna, 46, 1, pp. 141-156.

- (1997). «Montage as Posmodern Ironic Technique in Two Poems of Procedimientos narrativos by Ángel González», Letras Peninsulares, 2-3, pp. 277-307.

Fortuny, Francisco (2002). «De la maldad del mundo y de la divinidad del amor y de la música en la poesía de Ángel González», Litoral [«Ángel González. Tiempo inseguro»], 233, pp. 217-218.

Gahete Jurado, Manuel (2003). «Ángel González, la plenitud del vacío", Ars et Sapientia, 12, pp. 197-200.

Gallardo, José Luis (1976). «Reseña de Tratado de urbanismo», La Provincia, 11 de julio.

Gallego, Antonio (2002). «Ángel González músico», Litoral

[«Ángel González. Tiempo inseguro»], 233, pp. 219-223.

Gallego,Vicente (1986). «Notas sobre la poesía de Ángel González»,

suplemento «El dominical», Las Provincias, 7 de diciembre. 
— (2005). «Ángel González, caballero del verso», Zurgai

[«Con Ángel González»], junio, p. 13.

García de Cañuelo, Luis (1993). «Impresión de Ángel González», Ínsula, 553, pp. 53-55.

García de la Concha,Víctor (1996). «Introducción», en Luz, o fuego,

o vida, Salamanca, Universidad, pp. 9-62; el capítulo titulado «Segundo

tiempo: de Breves acotaciones a Prosemas» se reproduce en Litoral ["Ángel

González. Tiempo inseguro»], 233 (2002), pp. 224-229.

- (1998). «Lecciones de cosas y otros poemas», ABC literario, 23 de enero.

García Hortelano, Juan (1997). «Casuística angelológica», Luna de Abajo [«Guía para un encuentro con Ángel González»], 3, 3. a ed. aum., pp. 24-25; reproducido en Litoral [«Ángel González. Tiempo inseguro»], 233 (2002), pp. 150-152.

García Martín, José Luis (1986). «Ángel González», en La segunda generación poética de posguerra, Badajoz, Diputación, 1986, pp. 125-130 y 194-204.

— (1992). «Adverbios temporales», La Nueva España, 29 de mayo.

- (1985). «La generación del medio siglo (Prosemas o menos)», El Ciervo, 415-416, pp. 53-54.

- (1997). «Cuestión de procedimiento. La poesía última de Ángel González», Luna de Abajo [«Guía para un encuentro con Ángel González»], 3, 3. ed. aum., pp. 59-68.

- (2001). «Luz de otoño», El Mundo, 2 de mayo, p. 7.

— (2005). «Crítica literaria y aventura personal», en Ángel González,

La poesía y sus circunstancias, Barcelona, Seix-Barral, pp. 5-22.

García Montero, Luis (1993). «Impresión de Ángel González», Ínsula, 553, pp. 25-26.

— (1993). «Historia y experiencia en la poesía de Ángel González», en El realismo singular, Bilbao, Instituto Vasco de las Artes y las Letras, pp. 93-120; recogido en VV. AA., Actas del Congreso Jaime Gil de Biedma y su generación poética, II, [Zaragoza], Diputación General de Aragón, 1996, pp. 377-390; reproducido en Ángel González, un clásico de nuestro tiempo, coords. José Guerrero, Elena Peregrina y Álvaro Salvador, Almería, Universidad, 2004, pp. 27-40; recogido en Litoral [«Ángel González. Tiempo inseguro»], 233 (2002), pp. 230-239.

— (1995). «Ángel González», El País, 1 de noviembre.

- (1997). «Otra copa más con Ángel González», en Luna de Abajo [“Guía para un encuentro con Ángel González»], 3, 3. a ed. aum., pp. 68-70.

- (1999). «Soledades y palabras (Sobre Antonio Machado y Ángel González)», prólogo a Ángel González, Antonio Machado, Madrid, Alfaguara, pp. 15-40.

- (2002). «Ángel González», El Maquinista de la Generación, 5-6, pp. 202-205.

— (2007). «El pudor de Ángel», Cuadernos Hispanoamericanos, 680, pp. 31-34. 
— (2008). «Ángel, me dicen: sobre la utilidad de las palabras», Cuadernos

Hispanoamericanos [«Los Complementarios. Ángel González»], Extra 17, pp. 22-36.

García-Nieto Onrubia, María Luisa (1987). «Notas sobre los efectos expresivos en la poesía de Ángel González», Iris, 2, pp. 39-85.

García Posada, Miguel (1997). «Un modelo», suplemento «Babelia», El País, 22 de marzo.

— (2001). «Versos crepusculares», suplemento «Babelia», El País, 12 de mayo.

García SÁnchez, Jesús (2002). «Ángel González», Litoral [«Ángel

González. Tiempo inseguro»], 233, pp. 183-184.

— (2008). «La Kon Tiki», Cuadernos Hispanoamericanos [«Los

Complementarios. Ángel González»], Extra 17, pp. 42-49.

Gelman, Juan (2008). «Medio», Cuadernos Hispanoamericanos [«Los

Complementarios. Ángel González»], Extra 17, pp. 105-106.

Gil de Biedma, Jaime (1997). «Ángel», Luna de Abajo ["Guía para un encuentro con Ángel González»], 3, 3. a ed. aum., pp. 26-27; reproducido en Litoral [«Ángel González. Tiempo inseguro»], 233 (2002), pp. 138-139.

GonzÁlez Espina, Carlos (1983). «Anotaciones a una antología

poética de Ángel González», La Nueva España, 30 de enero.

GonzÁlez Muela, Joaquín (1972). «La poesía de Ángel González en su primera época», en Homenaje a Casalduero: crítica y poesía, eds. R. Pincus Sigele y Gonzalo Sobejano, Madrid, Gredos, pp. 189-199.

GonZÁLez-Gerth, Miguel (1977). «Introducción», en Ángel González, «Thirteen Poems and Some Drawings», The Texas Quarterly, pp. 7-10.

Goytisolo, José Agustín (1997). «Elogio nada desmedido de Ángel González», Luna de Abajo ["Guía para un encuentro con Ángel González»], 3, 3. ${ }^{a}$ ed. aum., pp. 31-33.

Grandes, Almudena (2002). «Mucho más guapo que Clark (Un cuento para Ángel González)», Litoral [«Ángel González. Tiempo inseguro»], 233, pp. 305-308.

- (2008). «Ángel, por ahora», Cuadernos Hispanoamericanos [«Los

Complementarios. Ángel González»], Extra 17, pp. 37-41.

Guelbenzu, José María (1968). «Reseña de Palabra sobre palabra», Cuadernos para el Diálogo, diciembre, p. 45.

Guerra, Pedro (2005). «Ángel González, poeta», Zurgai

[«Con Ángel González»], junio, p. 14.

GuindA, Ángel (1992-1993). «La poesía humanizante de Ángel

González», en Poesía en el Campus [«Ángel González»], 24, p. 9.

Hernández Alonso, Salvador (1985). «Prosemas o menos», Ínsula, 468, p. 18. 
Hierro, José (1997). «Sobre Ángel González», El Mundo, 24 de marzo.

Iravedra Valea, Araceli (2000). «La presencia de Antonio Machado en el grupo poético de los 50:Ángel González», en Homenaje a José María Martínez Cachero II: investigación y crítica, Oviedo, Universidad, pp. 839-858.

- (2005). «Entre las voces, una. Procedimientos machadianos de Ángel González», Zurgai [«Con Ángel González»], junio, pp. 86-96.

- (2008). "Ángel González y el pleito de la poesía», Cuadernos Hispanoamericanos [«Los Complementarios. Ángel González»], Extra 17, pp. 68-83.

Izquierdo, Luis (1967). «Notas a la poesía de Ángel González», Destino, 1554.

— (1977). «Plenitud de Grado elemental», El País, 17 de abril, p. 23.

— (1982). «Preámbulo retrospectivo», en Antología poética, Madrid, Alianza.

JiméneZ, José Olivio (1972). «De la poesía social a la poesía crítica: a propósito de Tratado de urbanismo (1967), de Ángel González», en Diez años de poesía española.1960-1970, Madrid, Ínsula, pp. 281-304.

Jiménez León, Marcelino (1998). «Amor y palabra en Ángel González», Poiesis. Revista de Crítica y Creación Poética, 7, pp. 76-81.

Jiménez Millán, Antonio (2002). «Ángel González: crónicas y notas de un viajero», Litoral [«Ángel González. Tiempo inseguro»], 233, pp. 240-243.

Jurado Morales, José (2010). «Antonio Machado en el Ángel González de Collioure», Ínsula, 768, pp. 3-6.

Kolker, Marielena (1979). «Con Ángel González: Primer encuentro», Prismal/Cabral, 3-4, pp. 47-59.

LABra, Ricardo (1990). «Tempus irreparabile fugit», Anthropos [«Ángel González. Una poética de la experiencia y la cotidianidad»], 109, pp. 116-117.

— (1996). «Ángel González, con P de poeta», El Comercio, 28 de enero.

- (2002). «Una lectura emocional de la poesía de Ángel González», Litoral [«Ángel González. Tiempo inseguro»], 233, pp. 251-259.

Lada Ferreras, Ulpiano (2005). «La poética de los antipoetas: Ramón de Campoamor, Nicanor Parra y Ángel González», en La literatura hispanoamericana más allá de sus fronteras, coords. Álvaro Arias y Ulpiano Lada, Oviedo, Gobierno del Principado de Asturias, pp. 69-88.

Lanz Rivera, Juan José (2005). «Poéticas en litigio: Ángel González y la crítica de la estética novísima», Zurgai [«Con Ángel González»], junio, pp. 72-78.

— (2008). «Ángel González o la búsqueda de la identidad en disolución», Iberoromania, 67, pp. 11-42. 
Lasheras, Javier (2008). «La emoción de la lucidez», en Lúcido Ángel.

Ángel González (1925-2008). Exposición bibliográfica, coord. Javier

Lasheras, Oviedo, Biblioteca Pública de Asturias, pp. 12-24.

Lázaro, Jesús (1984). «La palabra, siempre», Peña Labra. Pliegos de Poesía, 52, pp. 20-24.

Le Bigot, Claude (2005). «La forma breve en la obra poética de Ángel

González», Zurgai [«Con Ángel González»], junio, pp. 122-130.

LEUCI,Verónica (2006). «Entre la tradición y la renovación:Ángel

González y la reescritura retórica», Tropelías, 15-17, pp. 323-332.

- (2006). «De constantes y variantes: la propuesta bucólica de Ángel González», Espéculo,

33. http://pendientedemigracion.ucm.es/info/especulo/numero33/angonzal.html.

- (2007). «La poesía en el tiempo. Ángel González y la tradición», en Lo vivo

lejano, coord. Marcela Romano, Mar del Plata, EUDEM, pp. 103-121.

- (2008). «Ángel González: la cifra de múltiples versiones», Cuadernos

para Investigación de la Literatura Hispánica, 33, pp. 303-316.

— (2009). «La “Oda a los nuevos bardos” de Ángel González: parodia y tradición»,

Cuadernos para Investigación de la Literatura Hispánica, 34, pp. 421-432.

Lombardero, Manuel (1996). «El largo viaje del poeta amigo»,

en Asturias y los poetas, Oviedo, Nobel, pp. 349-354.

- (1997). «Dos fotografias», Luna de Abajo ["Guía para un encuentro

con Ángel González»], 3, 3. a ed. aum., pp. 12-16.

- (1997). «Ángel felizmente humano», La Nueva España, 5 de noviembre.

— (2002). «Ángel González 1938-1945», Litoral [«Ángel

González. Tiempo inseguro»], 233, pp. 172-177.

— (2004). «Memoria de Ángel González», en Ángel González, un clásico de nuestro tiempo, coords. José Guerrero, Elena Peregrina y Álvaro Salvador, Almería, Universidad, pp. 13-26.

- (2008). «De nuevo a Páramo del Sil», Cuadernos Hispanoamericanos

[«Los Complementarios. Ángel González»], Extra 17, pp. 61-62.

López Castro, Armando (1999). «La actitud escéptica de Ángel González», en La voz en su enigma. Cinco poetas de los años sesenta, Madrid, Pliegos, pp. 165-199;

reproducido en VV. AA., Homenaje a José María Martínez Cachero:

investigación y crítica, III, Oviedo, Universidad, 2000, pp. 9-42.

López de AbIADA, José Manuel (1990). «La ironía como rasgo generacional definidor en los comienzos del grupo del 50: apostillas a tres poemas representativos de José Agustín Goytisolo, Jaime Gil de Biedma y Ángel González», Diálogos Hispánicos, 9, pp. 45-56.

LuIs, Leopoldo de (1962). «Sin esperanza, con convencimiento de Ángel

González», Papeles de Son Armadans, XXIV, 70, pp. 124-126. 
Luti, Francesco (1999). «Nel nido del cuore», Caffé Michelangiolo, Anno 4, 2, pp. 4-13.

- (2001). «Senza speranza, con convizione. La poesia di

Ángel González», Poesia, 154, pp. 31-44.

— (2001). «Sulla poesia di Ángel González», Il Portolano, 27-28, pp. 5-13.

Mainer, José-Carlos (1992-1993). «De una teoelegía y una coincidencia», en Poesía en el Campus [«Ángel González»], 24, pp. 18-20.

— (2002). «Lázaro, el resucitado, insistiendo en Ángel González»,

Litoral [«Ángel González. Tiempo inseguro»], 233, pp. 260-266.

MaKris, Mary (1991). "Intertextualidad, discurso y ekfrasis en "El Cristo de Velázquez" de Ángel González», en En homenaje a Ángel González: ensayos, entrevista, poemas, ed. Andrew P. Debicki y Sharon Keefe Ugalde, Boulder, University of Colorado, pp. 73-83.

— (1991). «Ángel González's "Palabras desprendidas de pinturas de José Hernández": A Verbal-Visual Collage», en VV.AA., Selected Proceedings of the ThirtyNinth Annual Mountain Interstate Foreign Language Conference, Clemson UP.

- (1993). «Collage as metapoetry in Ángel González’s "Palabras desprendidas de pinturas de José Hernández"», Anales de la Literatura Española Contemporánea, XVIII, 1, pp. 157-172.

— (2000). «The “Gift of Gap”: Puns in Ángel González’s

Poetry", Hispanic Poetry Review, 2, pp. 106-123.

Mandlove, Nancy (1983). "Used Poetry: The Trans-Parent Language of Gloria Fuertes and Ángel González», Revista Canadiense de Estudios Hispánicos, 7, pp. 301-306.

MARCo, Joaquín (1972). «Ángel González: La palabra sobre palabra, expresión de una conciencia», La Vanguardia Española, 26 de octubre.

— (1975). «Juan Ramón Jiménez por Ángel González», La Vanguardia Española, 23 de enero.

Marfil, J. (1977). «Ángel González, un poeta español en Estados Unidos», Mundo Hispánico, 351, pp. 66-68.

Margarit, Joan (2008). «Orden», Cuadernos Hispanoamericanos [«Los Complementarios. Ángel González»], Extra 17, pp. 106-107.

Marra-López, José Ramón (1962). «La colección Colliure.

Poesía de compromiso», Ínsula, 231, p. 4.

Marsé, Juan (1997). «Primera memoria de Ángel con guitarra», Luna de Abajo [ «Guía para un encuentro con Ángel González»], 3, 3. a ed. aum., pp. 13-16; reproducido en Litoral [«Ángel González. Tiempo inseguro»], 233 (2002), pp. 142-143.

- (2008). «De copas con Ángel», Cuadernos Hispanoamericanos [«Los

Complementarios. Ángel González»], Extra 17, pp. 14-16. 
Martin, Sara A. (1991). «La experiencia desfamiliarizada en Sin esperanza, con convencimiento", en En homenaje a Ángel González: ensayos, entrevista, poemas, ed. Andrew P. Debicki y Sharon Keefe Ugalde, Boulder, University of Colorado, pp. 59-72.

Martín Gaite, Carmen (1977). «La muestra de Ángel

González», Diario 16, 9 de septiembre.

- (1990). «Bodas de oro con la vida. Ensayo sobre el poeta Ángel

González», El País, 21 de enero; reproducido en Litoral [«Ángel

González. Tiempo inseguro»], 233 (2002), pp. 267-270.

Martínez Álvarez, Josefina (1987). «Preámbulo a una conferencia», en Ángel González: Verso a verso, Oviedo, Caja de Ahorros de

Asturias («Colección Libro-Homenaje»), pp. 46-47.

Martínez García, José Antonio (1984). «Los poemas-

“chiste” de Ángel González», Ástura, 2, pp. 83-89.

Martino, Florentino (1970). «La poesía de Ángel González»,

Papeles de Son Armadans, LVII, 171, pp. 229-247.

— (1970). «Ángel González: Palabra sobre palabra», Revista de Occidente, 82, pp. 113-115.

Masoliver Ródenas, Juan Antonio (2001). «Lecciones

de experiencia», La Vanguardia, 1 de junio.

Matute, Ana María (2008). «El hombre delicioso», Cuadernos Hispanoamericanos

[«Los Complementarios. Ángel González»], Extra 17, pp. 10-13.

McAllister Hull, R. (1987). «Poetry: The voice of truth and agency of salvation», en Simposio-homenaje a Ángel González, eds. Susana Rivera y Tomás Ruiz Fábrega, Madrid, José Esteban, pp. 11-21.

Mediavilla, José Luis (1987). «Ángel González o la historia de un río que avanzaba de espaldas», en Ángel González:Verso a verso, Oviedo, Caja de Ahorros de Asturias («Colección Libro-Homenaje»), pp. 29-45.

Mesa Toré, José Antonio (2002). «Pero jamás en el mismo día», Litoral [«Ángel González. Tiempo inseguro»], 233, pp. 178-180.

Miller, Martha LaFollette (1982). «Literary Tradition Versus Speaker Experience in the Poetry of Ángel González», Anales de la Literatura Española Contemporánea, 7, pp. 79-96.

— (1985). «Political Intent Versus Verbal Play in "La paloma” by Ángel

González», Perspectives on Contemporary Literature, 11, pp. 93-99.

— (1988). «The Ludic Poetry of Ángel González», en After the War: Essays

on Recent Spanish Poetry, eds. Salvador Jiménez Fajardo and John C. Wilcox, Boulder, Society of Spanish and Spanish-American Studies, pp. 75-82. 
— (1991). «Inestabilidad temporal y textual en Ángel González», en En homenaje a Ángel González: ensayos, entrevista, poemas, ed. Andrew P. Debicki y Sharon Keefe Ugalde, Boulder, University of Colorado, pp. 113-128.

- y Rodríguez, Alfredo (1977-1978). «Aproximación a Grado elemental de Ángel González», Archivum, XXVII-XXVIII, pp. 121-140.

Miralles Meliá, Francisca (1990). «Lo que pasa en Ángel González», Anthropos [«Ángel González. Una poética de la experiencia y la cotidianidad»], 109, pp. 110-114.

Miró, Emilio (1966). «Palabra sobre palabra», Ínsula, 231, p. 5.

- (1967). «Tratado de urbanismo», Ínsula, 250, p. 7.

- (1969). «Palabra sobre palabra», Ínsula, 270, p. 6.

Molitoris, Joan I. (1989). «Diferencias críticas: el continuo críticolírico en Ángel González, Claudio Rodríguez y Jaime Gil de Biedma», Romance Languages Annual,1, pp. 553-558.

Mora, Ángeles (2004). «El desafio cotidiano o la poesía de Ángel González», en Ángel González, un clásico de nuestro tiempo, coords. José Guerrero, Elena Peregrina y Álvaro Salvador, Almería, Universidad, pp. 109-111.

Morante, José Luis (1997). «La palabra en el tiempo de Ángel González», El Correo de Andalucía, 4 de abril, pp. 24-25.

Moreno, Antonio (2004). «La poesía de Ángel González, una viva historia», en Los espejos del domingo y otras lecturas de poesía, Sevilla, Renacimiento, pp. 175-191.

MunÁrriz, Miguel (2008). «Ángel», Cuadernos Hispanoamericanos [«Los Complementarios. Ángel González»], Extra 17, pp. 108-109.

Olalla, Inés (2001). «Tiempo y espacio», Mercurio, 28 de junio.

Oliván, Lorenzo (1999). «La poesía de Ángel González», en Poesía española del medio siglo, edición no venal, Santander, La Isla de los Ratones, pp. 97-111.

— (2001). «La trama de la vida», suplemento «ABC Cultural», $A B C, 7$ de julio, p. 18.

Olmo Iturriarte, Almudena del (2012). «Cuatro compases más y otra vez solos: la música en la poesía de Ángel González», en Écfrasis e imitación artística en la poesía hispánica contemporánea: diez propuestas, coords. Francisco José Díaz de Castro y Almudena del Olmo Iturriarte, Sevilla, Renacimiento, pp. 83-110.

Ortega, J. (1984-1985). «Leer a Ángel González», Peña

Labra. Pliegos de Poesía, 53, pp. 17-18.

PAlley, Julian (1984). «Ángel González and the Anxiety of Influence», Anales de la Literatura Española Contemporánea, IX, 1-3, pp. 81-96.

PARKer, Stacey L. (1985). «Desfamiliarización en la poesía de Ángel González», Revista de Literatura Hispánica, 21, pp. 75-82. 
Paseyro, R. (1958). «Áspero mundo», Cuadernos, p. 108.

Payeras Grau, María (1979-1980). «La poética de

Ángel González», Mayurqa, 19, pp. 57-58.

- (1987). «Prosemas o menos: la última poesía de Ángel González», en Encuentros con el 50:

la voz poética de una generación, Oviedo, Fundación Municipal de Cultura, pp. 153-157.

- (1989). «Desde el fondo de una crisis: Breves acotaciones para una

biografía», en VV.AA., Miscel.lania d'homenatge a Francesca Massot $i$

Villalonga, Palma de Mallorca, Conselleria de Cultura.

— (1990). «Ángel González, un espíritu burlón», Anthropos [«Ángel González.

Una poética de la experiencia y la cotidianidad»], 109, pp. 35-44.

- (2000). «El rostro sobre la máscara. A propósito del sujeto poético

en la obra de Ángel González», en Poesía histórica y (auto)biográfica

(1975-1999), ed. José Romera, Madrid,Visor, pp. 454-465.

— (2000). «"Dato biográfico” de Ángel González», en Comentarios

de textos. Poetas del siglo XX, ed. Francisco J. Díaz de Castro, Palma

de Mallorca, Universitat de les Illes Balears, pp. 13-25.

- (2001). «Surgió en el aire limpio. El tema del amor en la poesía

de Ángel González», Campo de Agramante, 1, pp. 27-39.

- (2001). «Espejos de la historia», en De sombras y de sueños. Homenaje a José

María Castellet, ed. Emilio Salas, Barcelona, Península, pp. 290-308.

— (2002). «Ángel González: una mirada urbana», Litoral [«Ángel

González. Tiempo inseguro»], 233, pp. 271-277.

- (2006). «Palabra sobre palabra. Pensamiento y evolución

poética en Ángel González», La Página, 66, pp. 3-36.

- (2010). «Lecciones y elecciones. Blas de Otero en Ángel González y otros poetas del 50», en Compromisos y palabras bajo el franquismo. Recordando a Blas de Otero (1979-2009), eds. Araceli Iravedra y Leopoldo Sánchez Torre, Sevilla, Renacimiento, pp. 259-274.

PeÑa Lombao, Juanjo (2003). «La obra de Larkin y Ángel González», en

Estudios sobre literatura española contemporánea, coords. Moisés Castro, Rebeca

Díez, Ana María García, Carmen Mastache, Romina Pasandín, Ana María

Rodríguez y Eva Tizón, A Coruña, Universidade, pp. 133-144.

Persin, Margaret H. (1986). «Presencia contra ausencia en la primera

poesía de Ángel González», en Poesía como proceso: poesía española de los años 50 y 60, Madrid, Editorial José Porrúa Turanzas, pp. 119-147.

- (1988). «Différance in the Early Poetry of Ángel González», en After the War:

Essays on Recent Spanish Poetry, eds. Salvador Jiménez Fajardo y John C. Wilcox,

Boulder, Society of Spanish and Spanish-American Studies, pp. 67-74. 
Piera, C. (1985). «Ángel González y la función de la noche», El País, 30 de junio.

Prado, Benjamín (2001). «Ángel González», El País, 17 de mayo.

— (2002). «Cielo y abismo», Litoral [«Ángel González.

Tiempo inseguro»], 233, pp. 278-279.

- (2008). «Ángel González, la coherencia en sílabas contadas», Cuadernos

Hispanoamericanos [«Los Complementarios. Ángel González»], Extra 17, pp. 56-60.

Prieto de Paula, Ángel Luis (2002). «Ángel González, la fuerza del desaliento», Litoral [«Ángel González. Tiempo inseguro»], 233, pp. 278-283.

— (2005). «El realismo borroso de Ángel González (A propósito de "Historia apenas entrevista”)», Zurgai [«Con Ángel González»], junio, pp. 118-121.

Provencio, Pedro (1988). «Ángel González», en Poéticas españolas contemporáneas. La generación del 50, Madrid, Hiperión, pp. 19-41.

QuiÑonero, J. P. (1974). «Juan Ramón visto por Ángel

González», Informaciones, 5 de diciembre.

Rabal, Paco (1997). (sin título), en Luna de Abajo ["Guía para un encuentro con Ángel González»], 3, 3. ${ }^{a}$ ed. aum., pp. 47-48.

RegÀs, Rosa (2005). «Ángel González», Zurgai [«Con Ángel González»], junio, pp. 8-9.

Rico, Eduardo G. (1956). «Un joven poeta, un mundo

áspero", La Nueva España, 13 de enero.

— (1970). «La poesía de Ángel González», Triunfo, 7 de marzo.

Ríos Ruiz, M. (1967). «Tratado de urbanismo», Poesía Española, agosto.

Rioyo, Javier (2005). «Palabras para Ángel», Zurgai [«Con

Ángel González»], junio, pp. 10-11.

Rivera, Susana (1990). «Bibliografia de y sobre Ángel González», Anthropos [«Ángel González. Una poética de la experiencia y la cotidianidad»], 109, pp. 31-34.

— (1998). «Introducción», en Ángel González, Cincuenta años de periodismo a ratos y otras prosas, Oviedo, Nobel, pp. 7-24.

— (2002). «Presentación», Litoral [«Ángel González. Tiempo inseguro»], 233, pp. 6-13.

— (2002). «Bibliografía de Ángel González», Litoral [«Ángel

González. Tiempo inseguro»], 233, pp.1-15.

- (2004). «Intertextualidad y collage», en Ángel González, un clásico de nuestro tiempo, coords. José Guerrero, Elena Peregrina y Álvaro Salvador, Almería, Universidad, pp. 41-57.

- (2008). «Persona privilegiada», Cuadernos Hispanoamericanos [«Los

Complementarios. Ángel González»], Extra 17, pp. 7-9. 
Rodríguez, Alfredo (1987). «Ángel González, catedrático», en Ángel González:Verso a verso, Oviedo, Caja de Ahorros de Asturias («Colección Libro-Homenaje»), pp. 15-17. - (2002). «El poeta en su rincón universal», Litoral [«Ángel González. Tiempo inseguro»], 233, pp. 181-182.

— y Rebolledo, Diana (1987). «Escupiendo palabras: el conflictivo proceso creativo en Ángel González y José Ángel Valente», en Simposio-homenaje a Ángel González, eds. Susana Rivera y Tomás Ruiz Fábrega, Madrid, José Esteban, pp. 129-135.

Rodríguez, Claudio (1987). «Semiepístola ¿moral? a Ángel», en Ángel González: Verso a verso, Oviedo, Caja de Ahorros de Asturias («Colección Libro-Homenaje»), pp. 13-14; reproducido en Litoral [«Ángel González. Tiempo inseguro»], 233 (2002), pp. 140-141.

Rodríguez, Rubén D. (2001). «El Ángel de las palabras», La Nueva España, 17 de mayo.

Rodríguez Padrón, Jorge (1967). «Ángel González: Tratado de urbanismo», Cuadernos Hispanoamericanos, 216, pp. 674-680.

- (1974). «Juan Ramón Jiménez, de Ángel González», Triunfo, 21 de diciembre. Romano, Marcela (1994). «Ángel González: la voz en desconcierto», en La voz diseminada. Hacia una teoría del sujeto en la poesía española, eds. Laura Scarano, Marcela Romano y Marta Ferrari, Buenos Aires, Biblos, pp. 127-148.

— (1996). «Usos y costumbres de un Narciso "posmoderno”: la poesía autorreferencial de Ángel González», en Marcar la piel del agua. La autorreferencia en la poesía española contemporánea, eds. Marta Ferrari, Laura Scarano, Marcela Romano y Marta Ferreyra, Rosario, Beatriz Viterbo, pp. 103-115.

— (2002). «Ángel González, Otoños y otras luces», Diablotexto, 6, pp. 398-400.

- (2005). «L'aquexada passión de Ángel González», Zurgai

[“Con Ángel González»], junio, pp. 80-85.

Romero, Carmen (2008). «Ángel González, Nada grave. Superviviente hacia la desesperanza», La Estafeta del Viento, http://www.laestafetadelviento.es/resenas/nada-grave.

Rosa, Isaac (2008). «¿Para qué sirven los poetas?», Cuadernos Hispanoamericanos [«Los Complementarios. Ángel González»], Extra 17, pp. 98-103.

Rosales, José Carlos (2008). «El tiempo ajeno de Ángel González», Cuadernos Hispanoamericanos [«Los Complementarios. Ángel González»], Extra 17, pp. 63-67.

Rovira, Pere (1985). «Los Prosemas de Ángel González», Ínsula, 469, pp. 1 y 10; reproducido en Litoral [«Ángel González. Tiempo inseguro»], 233 (2002), pp. 286287; reproducido en Ángel González, un clásico de nuestro tiempo, coords. José Guerrero, Elena Peregrina y Álvaro Salvador, Almería, Universidad, 2004, pp. 59-64.

Ruiz Pérez, Ángel (2004). «Identidad, tradición y clasicismo en Ángel González», Anales de la Literatura Española Contemporánea, 29, pp. 283-306. 
Ruiz Pérez, Pedro (2001). «Ángel González: “Introducción a unos poemas elegíacos"», en Cien años de poesía. 72 poemas españoles del siglo XX: estructuras poéticas y pautas críticas, eds. Peter Fröhlicher, Georges Günter, Rita Catrina Imboden e Itziar López Guil, Berna, Peter Lang, pp. 491-504.

Sabadell Nieto, Joana (1998). «Consideraciones sobre autoría, subjetividad y sociedad en la poesía de Ángel González», en Actas del XII Congreso de la Asociación Internacional de Hispanistas, 21-26 de agosto de 1995, V, coord. Derek Flitter, Birmingham, University of Birmingham, pp. 231-236.

Sala Valldaura, Josep Maria (1972). «Palabra sobre palabra», Camp de l'arpa, 3, pp. 28-29. - (1993). «Primer y penúltimo Ángel González», en La fotografía de una sombra. Instantáneas de la generación poética de los 50, Barcelona, Anthropos, pp. 81-106.

Salas Franco, María Pilar (2006). «Ángel González, padrino del verso», Fábula, 21, pp. 74-76.

Salvador, Álvaro (1986). «Ángel González o la poética del pudor», Olvidos de Granada [«Palabras para un tiempo de silencio: La poesía y la novela de la generación del '50»], extra 13, pp. 74-78; reproducido en Las rosas artificiales. La búsqueda de la modernidad en la poesía hispánica, Sevilla, Fundación Genesian, 2003, pp. 255-270.

— (2002). «La palabra precisa de Ángel González», Litoral [«Ángel

González. Tiempo inseguro»], 233, pp. 288-292.

- (2004). «Avanzaba de espaldas aquel río», en Ángel González, un clásico de nuestro tiempo, coords. José Guerrero, Elena Peregrina y Álvaro Salvador, Almería, Universidad, pp. 65-67. — (2009). «El antipoeta Ángel González», Campo de Agramante, 12, pp. 85-101.

Salvago Lobato, Consuelo (2003). «El sentimiento amoroso frente a la angustia existencial en Áspero Mundo, de Ángel González», en Medicina y literatura: actas del II simposio interdisciplinar de medicina y literatura, Real Colegio Oficial de Médicos de la Provincia de Sevilla, 2 y 3 de mayo de 2002, coord. Esteban Torre, Sevilla, Padilla, pp. 311-318.

— (2003). «Visión de la muerte en la poética de Ángel González», en Medicina y literatura: actas del III simposio interdisciplinar de medicina y literatura, Real Colegio Oficial de Médicos de la Provincia de Sevilla, 3, 4 y 5 de abril de 2003, coord. Esteban Torre, Sevilla, Padilla, pp. 361-370.

- (2003). «La lectura como elemento esencial en la comunicación poética de Ángel González», en La recepción de los discursos: el oyente, el lector y el espectador, coords. José Antonio Hernández, María del Carmen García, Isabel Morales y Fátima Roca, Cádiz, Universidad, pp. 301-310.

SÁnChez CARrón, Irene (2007). «Correlaciones del presente en la poesía de Ángel González», Espéculo, 35. https://pendientedemigracion. ucm.es/info/especulo/numero35/agonza.html. 
SÁnchez Torre, Leopoldo (2005). «La inversión de los géneros discursivos en Grado elemental, de Ángel González», Zurgai [«Con Ángel González»], junio, pp. 98-103.

SAnTos, Dámaso (1976). "Ángel González, El grupo poético del 27. Antología», Pueblo, 5 de noviembre.

SCARANO, Laura (2002). «Los paisajes urbanos de Ángel González», Litoral [«Ángel González. Tiempo inseguro»], 233, pp. 293-299.

- (2012). «Nada grave o grave nada: la mueca póstuma de Ángel González», Archivum, LXI-LXII, pp. 427-444.

Schumm, Sandra (1991). «El aspecto alusivo de la poesía de Ángel González», Hispanic Journal, 12, pp. 133-145.

Siebenman, Gustav (1973). «Ángel González», en Los estilos poéticos en España desde 1900, Madrid, Gredos, pp. 467-468.

Sierra, José Luis (1984). «Ángel González: realidad y sarcasmo», Plural, 155, pp. 52-56.

Silva Cienfuegos-Jovellanos, Pedro de (1997). «Exactitud, hondura, sarcasmo», en Luna de Abajo ["Guía para un encuentro con Ángel González»], 3, 3. ${ }^{a}$ ed. aum., pp. 44-46.

Silver, Philip (1987). «What are poets for?», en Simposio-homenaje a Ángel González, eds. Susana Rivera y Tomás Ruiz Fábrega, Madrid, José Esteban, 1987, pp. 83-94.

Simonatti, Selena (2008). «Le derivazioni imperfette e l'armonia ricostruita: un camino nella poesia con Ángel González», Rivista de Filologia e Letterature Ispaniche, 11, pp. 203-218; recogido en Deletreos de armonía. Ensayos de poesía española contemporánea, coords. Aldo Ruffinatto, Guillermo Carrascón, Iole Scamuzzi y Selena Simonatti, Madrid, Calambur, 2013.

Sobejano, Gonzalo (1987). «Salvación de la prosa, belleza de la necesidad en la poesía de Ángel González», en Simposio-homenaje a Ángel González, eds. Susana Rivera y Tomás Ruiz Fábrega, Madrid, José Esteban, pp. 21-54.

- (1991). «Un prosema de Ángel González, más ciertas precisiones», en En homenaje a Ángel González: ensayos, entrevista, poemas, ed. Andrew P. Debicki y Sharon Keefe Ugalde, Boulder, University of Colorado, pp. 85-96.

- (1991). «Para que yo me llame Ángel González», en El exilio de las Españas de 1939 en las Américas: “¿Adónde fue la canción?», coord. José María Naharro-Calderón, Barcelona, Anthropos, pp. 191-194.

— (2002). «Ángel González: su nombre y los nombres», Litoral [«Ángel González. Tiempo inseguro»], 233, pp. 300-302.

- (2009). «Ángel González con Antonio Machado», Ínsula [«Colliure, 1959»], coord. Araceli Iravedra, 745-746, pp. 14-16.

Solar, H. del (1968). «Ángel González: Palabra sobre palabra», El Mercurio, 13 de octubre. 
SuÁrez Coalla, Francisca (1996). «Las voces silentes de Ángel González», en Actas del Congreso Jaime Gil de Biedma y su generación poética, II, [Zaragoza], Diputación General de Aragón, pp. 391-396.

Sueiro, Daniel (1997). "Ángel más poeta», en Luna de Abajo ["Guía para un encuentro con Ángel González»], 3, 3. a ed. aum., pp. 39-40.

SuÑén, Luis (1985). «La realidad y las palabras de Ángel González», El País, 15 de junio.

TAibo I, Paco Ignacio (1988). «Prólogo y nota biográfica», en Ángel González, $A$ todo amor, México, UNAM; reproducido en $A$ todo amor, Madrid,Visor, 1997.

— (1991). «A todo amor. Notas sobre la poesía amorosa de Ángel González y su nacimiento como poeta», en En homenaje a Ángel González: ensayos, entrevista, poemas, ed. Andrew P. Debicki y Sharon Keefe Ugalde, Boulder, University of Colorado, pp. 99-109.

- (1997). «Ángel en Páramo», Luna de Abajo ["Guía para un encuentro con Ángel González»], 3, 3. ․ ed. aum., pp. 7-10.

— (2002). «Los años reconstruidos», Litoral [«Ángel González.

Tiempo inseguro»], 233, pp. 186-188.

Ugalde, Sharon Keefe (1995). «Hybrid Poetics and the Female Tradition: Refractions of Ángel González in the Poetry of Ángeles Mora», Revista Hispánica Moderna, XLVIII, 1, pp. 181-188.

— (2002). «La sombría claridad», Litoral [«Ángel González.

Tiempo inseguro»], 233, pp. 244-250.

- (2004). «El claroscuro», en Ángel González, un clásico de nuestro tiempo, coords. José Guerrero, Elena Peregrina y Álvaro Salvador, Almería, Universidad, pp. 69-85.

Umbral, Francisco (1968). «Palabra sobre palabra de Ángel González», Poesía Española, 191. Valente, José Ángel (1965). «Ángel González», Índice, 88-89 (mayo-junio), p. 12.

Villa Pastur, Jesús (1956). «Áspero mundo», La Voz de Asturias, 27 de septiembre.

Villán, J. (1976). «Ángel González, una memoria acusadora», Arriba, 2 de diciembre.

Villanueva, Tino (1980). «Áspero mundo de Ángel González: de la contemplación lírica a la realidad histórica», Journal of Hispanic Studies: Twentieth Century, I-II, 8, pp. 161-180.

- (1983). «Censura y creación: dos poemas subversivos de

Ángel González», Hispanic Journal, 5, pp. 49-72.

- (1988). «Ángel González: de la contemplación lírica a la poesía subversiva», en Tres poetas de posguerra: Celaya, González y Caballero Bonald (Estudio y entrevistas), London, Tamesis Books.

Villar, Arturo del (1975). «Vida, poesía y pintura de Juan Ramón Jiménez», La Estafeta Literaria, 556, 15 de enero. 
Villena, Luis Antonio de (1996). «Un bohemio en la Academia», El Mundo, 26 de enero.

- (1997). «Sabidurías de amor», El Mundo, 1 de febrero.

— (2001). «El fiel de la ternura», El Mundo, 10 de julio.

- (2002). «Ángel González, recuerdos y celebraciones», Litoral

[«Ángel González. Tiempo inseguro»], 233, pp. 189-192.

Vilumara, Martín (1968). «Ángel González: Palabra sobre palabra», Si

la píldora bien supiera, no la doraran por defuera, 4, pp. 178-182.

Wilcox, John C. (2003). «Ángel González’s Intertextualization of Juan Ramón Jiménez», en The Discovery of Poetry. Essays in Honor of Andrew P. Debicki, ed. Roberta Johnson,

Boulder, CO, The Society of Spanish and Spanish-American Studies, pp. 35-59.

Wood, Michael (1978). «The Insulted and Injured», The New

York Review of Books, XXV, 20-21, pp. 20-21.

Yáñez, Ma Paz (2002). «Distancia y participación en la poesía de

Ángel González», Cuadernos del Lazarillo, 22, pp. 60-64.

\section{ENTREVISTAS}

Agrriano, Jon (1997). «Ángel González, poeta y académico. "Solo la memoria nos sirve de lección”", El Correo de Bilbao, 6 de abril.

Alameda, Sol (2001). «Ángel González. El poeta cercano»,

El País Semanal, 1 de julio, pp. 8-16.

Alvarado Tenorio, A. (1980). «Con Ángel González», en La poesía

española contemporánea (Á. González, J. M. Caballero Bonald, C. Barral, J.

Gil de Biedma y F. Brines), Bogotá, La Oveja Negra, pp. 81-89.

Álvarez, Faustino F. (1983). «Conversación con Ángel González», en Una

antología, Oviedo, Automóviles Luarca S. A. (edición no venal); 2. ${ }^{a}$ ed. 1985.

Avello, Manuel F. (1968). «Para que yo me llame Ángel

González», La Nueva España, 31 de julio.

Bello, Xuan (2008). "Ángel González: la última carta»,

Clarín. Revista de Nueva Literatura, 73, pp. 38-46.

Bermejo, José María (2001). «Ángel González: “Vivimos en el barrio

de lujo de la aldea global”", La Clave, julio, pp. 80-83.

Brown, Steven Ford y Gutiérrez Revuelta (i974). «An Interview

with Ángel González», Paintbrush. A Journal of Poetry, Translations and

Letters, NorthEast Missouri University, XVIII, 36, pp. 35-42. 
Campbell, Federico (1971). «Ángel González o la desesperanza», en Infame turba, Barcelona, Lumen, pp. 367-379.

Carriedo Castro, Pablo (2007). «"La poesía, aunque no sea capaz de derribar un régimen, no deja de transformar el mundo": encuentro con Ángel González», Lectura y Signo, 2, pp. 395-408.

Castilla, Leopoldo (1978). «Poema sobre poema», La Calle, agosto.

Castillo, Javier del (1966). «Entrevista, Ángel González», Tribuna, 19 de enero.

Chirbes, Rafael y Puértolas, Ana (1968). «La poesía de lenguaje cotidiano», Cuadernos para el Diálogo, 2 de septiembre.

Claudín,Víctor y González Calero, Alfonso (1978). «Ángel González, poeta: Con esperanza sin convencimiento», Ozono, pp. 50-52.

Cruz Ruiz, Juan (1978). «Nueva edición de la obra completa de Ángel González», El País, 18 de junio.

— (1990). «Retrato del artista desolado», El País, 15 de enero.

Cuartas, Javier (1986). «Ángel González: “Soy un superviviente"», La Nueva España, 7 de octubre.

Erdocia Castillejo, Carolina, Beti, Arantxa y Amorós, Leonor (1986). «Ángel González, poesía desde la experiencia», Mundaiz, 31, pp. 117-124.

Fernández Braso, M. (1969). «Entrevista», Pueblo, 10 de septiembre.

García, Miguel Ángel (2002). «Camino a casa: entrevista con Ángel González», Doce Notas Preliminares. Revista de Música y Arte, 9, pp. 53-84.

García Montero, Luis (2002). «Conversación con Ángel González», Litoral [«Ángel González. Tiempo inseguro»], 233, pp. 15-27.

- (2007). «Cuestión de palabras. Conversación entre Luis García Montero y Ángel González sobre el aprendizaje poético», Cuadernos Hispanoamericanos, 680, pp. 35-41.

García Ortega, A. (1986). «La ausencia de la dicha», El País, 28 de agosto.

Hernández, Juan José (1971). «Entrevista», La Gaceta,

San Miguel de Tucumán, 5 de diciembre.

Herrero, Eduardo (2002). «Ángel González: “Escribo versos, escribo palabras”», El Maquinista de la Generación, 5-6, pp. 166-174.

Ibarrondo, Patxi (1988). «Ángel González: “En la España de hoy se han olvidado muchas cosas"», Cambio 16,1398, pp. 74-75.

Iravedra, Araceli (2009). «Ángel González, un maestro vivo. Respuestas inéditas a un cuestionario», Ínsula, 745-746, pp. 16-17. 
LeÓn, María Eugenia (1995). «Ángel González: “El alcohol no es una fuente de inspiración, sino de molestas resacas"», Tribuna de Actualidad, 14 al 20 de agosto.

LeÓN-Sotelo, Trinidad de (1996). «Ángel González: "La

lógica es el absurdo"", $A B C, 28$ de enero.

López-VegA, Martín (2001). «Ángel González de estreno: “La realidad te obliga a reinventarte"», suplemento «El Cultural», El Mundo, 2 de mayo, pp. 8-9.

MARFIL, Jorge A. (1976). «Charla informal con un poeta», Triunfo, 725, 18 de diciembre, pp. 64-65.

— (1977). «Ángel González: presencia de un poeta mayor», El viejo topo, 11, pp. 64-65.

Mora, Rosa (1997). «Ángel González, un poeta contra el olvido», suplemento «Babelia», El País, 22 de marzo.

Morante, José Luis (1997). «Una conversación con Ángel González. El poeta como invención del lector», Prima Littera, 1, pp. 42-46; recogida en Palabras adentro (23 entrevistas literarias), Lucena, Ayuntamiento de Lucena, Anexo I de la Colección «Cuatro Estaciones», 2003, pp. 29-35.

MunÁrriz, Miguel (1997). «Ángel González», El Mundo, 22 de marzo.

Palou, Josep (1995). «Ángel González: "Nada es inútil en el arte”», El País, 31 de julio.

Paz Paredes,Y. (1970). «El poeta Ángel González», El Nacional, 11 de octubre.

Rivas, Manuel (1996). «Monseñor y el poeta. El presidente de la Conferencia Episcopal conversa con el escritor y académico de la lengua Ángel González», El País, 4 de agosto.

Rodríguez, Gracia (1984). «Ángel fieramente humano», Quimera, enero, pp. 23-29.

Rubiera, Pilar (1992). «Los “poemas de la vejez” de Ángel

González», La Nueva España, 29 de mayo.

SCARANO, Laura (2003). «De los álamos vengo...: Entrevista al poeta español Ángel González», Olivar, 4. 4, pp. 161-175.

Solanes, Ana (2008). «Entrevista con Ángel González», Cuadernos Hispanoamericanos, 692, pp. 119-140.

Somovilla, Miguel (1987). «Breves acotaciones para una biografia», en Ángel González: Verso a verso, Oviedo, Caja de Ahorros de Asturias («Colección Libro-Homenaje»), pp. 97-139.

TAıвo I, Paco Ignacio (1970). «Ángel González y las buenas palabras», El Universal, México DF, junio.

Togores, Ana (2000). «Ángel González, poeta: "Hay editoriales sin vida, metes un libro y es como tirarlo"», Escuela Pública, 6, pp. 34-35. 
UGALDE, Sharon K. (1991). «Entrevista a Ángel González», en En homenaje a Ángel González: ensayos, entrevista, poemas, ed. Andrew P. Debicki y Sharon Keefe Ugalde, Boulder, University of Colorado, pp. 111-125.

Villanueva, Tino (1988). «Entrevista a Ángel González», en Tres poetas de posguerra: Celaya, González y Caballero Bonald (estudio y entrevistas), Londres, Tamesis Books pp. 332-347.

VIVAs, A. (1985). «La vitalidad de la poesía», Leer, 2, 2 de octubre.

\section{TESIS DOCTORALES}

Baena, Enrique (1983). La poesía de Ángel González, Universidad de Málaga.

Browne, Peter E. (1991). Semiotic Aspects of the Poetry of Gloria Fuertes and Ángel González, The University of Nebraska, Lincoln.

Candel Vila, Consuelo (2001). El realismo dialéctico en las poéticas de Luis Rosales, Ángel González y Luis García Montero, Universidad de Valencia.

Carriedo Castro, Pablo (2005). Ángel González. Once años de poesía, 1956-1967 (Aproximación a su obra social bajo la dictadura del general Franco), Universidad de León.

Cochrane, Helena Antolín (1991). El ideal de perduración a través de la palabra poética en la poesía del 50 en España:Ángel González, José Ángel Valente, Jaime Gil de Biedma, University of Pennsylvania.

Deters, Joseph Michael (1997). Love and the Postmodern: The Poetry of Ángel González, University of Arizona.

Fisher, Diane Renee (1990). The Voices of Irony in the Poetry of Ángel González, The Ohio State University.

García Giraldos de Sprackling, Soledad (1989). Concordancia estilística de la obra de Ángel González, University of New Mexico.

LaCertua, Patrick J. (1983). Ángel González: Poetry as Craft and the «Word Upon Word» Experience, University of Kentucky.

Leuci, Verónica (2014). Poetas in-versos: ficción y nombre propio en Gloria Fuertes y Ángel González, Universidad Nacional de Mar del Plata.

Makris, Mary (1990). Under the Influence: Intertextual Strategies in the Poetry of Ángel González, Rutgers, The State University of New Jersey, New Brunswick.

Martin, Sara A. (1987). The Poetry of Ángel González: Standing With the Reader, Universidad de Kansas.

Molitoris, Joan Irene (1995). A Semiotics of Critical Opposition in the Poetry of Ángel González, Columbia University. 
Salvago Lobato, Consuelo (2006). La poética de Ángel González, Universidad de Sevilla.

Singleterry, Gary A. (1972). The Poetic Cosmovision of

Ángel González, University of New Mexico.

Valverde Rodríguez, Fernando (2011). Ángel González,

periodista, Universidad de Granada.

Villanueva, Tino (1981). Poesía de oposición entre 1955-1963 en Gabriel Celaya, Ángel González y José Manuel Caballero Bonald, Boston University.

Walochiк, Krista (1978). Ángel González, poeta de la segunda

generación de posguerra, Middlebury College. 